\title{
Prefrontal Cholinergic Mechanisms Instigating Shifts from Monitoring for Cues to Cue-Guided Performance: Converging Electrochemical and fMRI Evidence from Rats and Humans
}

\author{
William M. Howe, ${ }^{1 \star}$ Anne S. Berry, ${ }^{1 \star}$ Jennifer Francois, ${ }^{2 \star}$ Gary Gilmour, ${ }^{2}$ Joshua M. Carp, ${ }^{1}$ Mark Tricklebank, ${ }^{2}$ \\ Cindy Lustig, ${ }^{1}$ and Martin Sarter ${ }^{1}$ \\ ${ }^{1}$ Department of Psychology and Neuroscience Program, University of Michigan, Ann Arbor, Michigan 48109-1043, and ${ }^{2}$ Lilly Centre for Cognitive \\ Neuroscience, Eli Lilly and Co. Ltd., Erl Wood Manor, Windlesham GU20 6PH, Surrey, United Kingdom
}

\begin{abstract}
We previously reported involvement of right prefrontal cholinergic activity in veridical signal detection. Here, we first recorded real-time acetylcholine release in prefrontal cortex (PFC) during specific trial sequences in rats performing a task requiring signal detection as well as rejection of nonsignal events. Cholinergic release events recorded with subsecond resolution ("transients") were observed only during signal-hit trials, not during signal-miss trials or nonsignal events. Moreover, cholinergic transients were not observed for consecutive hits; instead they were limited to signal-hit trials that were preceded by factual or perceived nonsignal events ("incongruent hits"). This finding suggests that these transients mediate shifts from a state of perceptual attention, or monitoring for cues, to cue-evoked activation of response rules and the generation of a cue-directed response. Next, to determine the translational significance of the cognitive operations supporting incongruent hits we used a version of the task previously validated for use in research in humans and blood oxygenation level-dependent (BOLD)-functional magnetic resonance imaging. Incongruent hits activated a region in the right rostral PFC (Brodmann area 10). Furthermore, greater prefrontal activation was correlated with faster response times for incongruent hits. Finally, we measured tissue oxygen in rats, as a proxy for BOLD, and found prefrontal increases in oxygen levels solely during incongruent hits. These cross-species studies link a cholinergic response to a prefrontal BOLD activation and indicate that these interrelated mechanisms mediate the integration of external cues with internal representations to initiate and guide behavior.
\end{abstract}

\section{Introduction}

Traditional descriptions of cholinergic projections to the cortex as a relatively slow-acting neuromodulator system have been challenged by findings indicating that acetylcholine (ACh) release fluctuates at a subsecond-to-second resolution and mediates distinct behavioral and cognitive operations (Parikh et al., 2007; Sarter et al., 2009; Dayan, 2012). Specificity of cholinergic function may be supported by a topographically differentiated projection system (Zaborszky et al., 2005, 2008) and regionally and layer-specific integration of cholinergic inputs into cortical circuitry (Hasselmo and Bower, 1992; Couey et al., 2007; Hasselmo and Sarter, 2011; Disney et al., 2012). For example,

\footnotetext{
Received Dec. 19, 2012; revised March 21, 2013; accepted April 9, 2013.

Author contributions: M.T., C.L., and M.S. designed research; W.M.H., A.S.B., J.F., and G.G. performed research; W.M.H., A.S.B., J.F., G.G., J.M.C., and C.L. analyzed data; W.M.H., M.T., C.L., and M.S. wrote the paper.

This work is supported in part by Public Health Service Grants MH086530 and DA031656, and National Science Foundation (NSF) Grant 0726285. A.B. was supported by an NSF Graduate Research Fellowship. We thank the study participants and the staff of the University of Michigan fMRI Center. We thank Dr. J. Jonides (University of Michigan) for his comments on an earlier version of this article.

*W.M.H., A.S.B., and J.F. contributed equally to this work.

Correspondence should be addressed to Martin Sarter, University of Michigan, Department of Psychology, 4030 East Hall, 530 Church Street, Ann Arbor, MI 48109-1043. E-mail: msarter@umich.edu.

DOI:10.1523/JNEUROSCI.5809-12.2013

Copyright $\odot 2013$ the authors $\quad 0270-6474 / 13 / 338742-11 \$ 15.00 / 0$
}

consistent with a right-hemispheric cortical specialization for the detection of behaviorally relevant stimuli (Corbetta and Shulman, 2002; Demeter et al., 2011), right cortical cholinergic inputs are required for the detection of signals ("detection" defined in Posner et al., 1980; Martinez and Sarter, 2004). Here we report results specifying the role of right prefrontal cholinergic activity, suggesting it acts as part of a switch or "gateway" between monitoring for potential signals and activating signal (or cue)evoked behavior.

The first experiment reported here examined seconds-long cholinergic release events ("transients") during a task that required the detection of signals as well as the rejection of nonsignal events (the sustained attention task, SAT; McGaughy et al., 1996). As described below, we found that cholinergic transients were only generated on trial sequences involving shifts from nonsignal- to signal-directed responses (see Fig. 1, "incongruent hits"). This suggests that rather than being involved in all detections, right prefrontal cholinergic transients play a more specific role in shifts from perceptual attention, or monitoring, to signal-evoked (re)activation of signal-associated task rules and behavior.

The hypothesis that transient right prefrontal activity is associated with shifts from perceptual (also termed "external" or 
"stimulus-directed") to reflective (also termed "internal" or "goal-directed") attention finds strong parallels in the human neuroimaging literature, where distinctions between perceptual and reflective attention have been proposed as a central principle for understanding the organization of attentional systems (Corbetta and Shulman, 2002; Burgess, 2011; Chun and Johnson, 2011; Chun et al., 2011). To test whether the rodent findings of shift-related transient activity could be conceptually replicated in humans, our second study used blood oxygenation leveldependent (BOLD) functional magnetic resonance imaging (fMRI) and a human version of the SAT (Demeter et al., 2008, 2011) and found that shifts from nonsignal to signal-directed processing elicited right lateral orbitofrontal cortex activity that correlated with performance.

To further bridge findings across neural measures and species, a third experiment measured changes in tissue oxygen $\left(\mathrm{T}_{\mathrm{O} 2}\right)$ in rodents. $\mathrm{T}_{\mathrm{O} 2}$ levels are closely coupled to neuronal activity and thus have been suggested as a proxy for fMRI (Lowry et al., 2010; Li et al., 2011; Francois et al., 2012; McHugh et al., 2013). We again found sequence-specific transient responses, paralleling the rodent cholinergic and human fMRI results. Collectively, these experiments suggest that transient right prefrontal cortex (PFC) activation plays an important and specific role in shifts from monitoring to cue-directed response.

\section{Materials and Methods}

\section{Cholinergic transients}

Subjects. Subjects were male Wistar rats (Harlan; $n=5$ ) $\sim 60 \mathrm{~d}$ old and $200-300 \mathrm{~g}$ at the onset of training. Animals were kept on a 14/10 light/ dark cycle in a temperature- and humidity-controlled vivarium. Water was only available as a reward during testing and for 30 min upon the completion of the training/testing session. Animals were maintained in accordance with the National Institutes of Health Guide for the Care and Use of Animals and experiments were conducted using protocols approved by the University of Michigan Committee on Use and Care of Animals.

SAT training procedures. Animals were trained to perform the SAT as described previously (St Peters et al., 2011; Paolone et al., 2012). Briefly, the SAT is comprised of two basic trial types (signal and nonsignal), which occur with equal probability and in a randomized order (Fig. 1a). On a signal trial, following the $9 \pm 3 \mathrm{~s}$ intertrial interval (ITI), a visual signal $(500 \mathrm{~ms}, 50 \mathrm{~ms}$, or $25 \mathrm{~ms}$ duration) is presented via a centrally located stimulus light. Two seconds later both response levers are extended into the operant chamber as a cue for the animal to respond. Following signal trials, a press on the left lever is scored as a hit and rewarded (30 $\mu \mathrm{l}$ of water) while a press on the right lever is not. In the absence of a signal, a press on the right lever is scored as a correct rejection and rewarded while a response on the left lever is not. Half of all animals were trained with reverse rules. Failure to respond within $4 \mathrm{~s}$ was counted as an error of omission. Levers were withdrawn after a response or after $4 \mathrm{~s}$ passed. The final analyses were based on successful recordings from animals performing both sets of rules ( $n=3$ and 2, respectively). Training sessions were comprised of a total of 162 trials, half signal and half nonsignal. Signal and nonsignal trials were presented in a pseudorandomized order. Animals were trained on the final version of the task until performance reached a plateau. Only animals with $>70 \%$ hits for $500 \mathrm{~ms}$ signals and $>70 \%$ correct rejections were used in the present experiments. Upon demonstration of task proficiency, animals were acclimated to the test chamber. They were trained daily in the new environment until they re-established criterion level performance $(\sim 2$ weeks). After no fewer than 3 consecutive days of criterion level performance in the test chamber, animals were implanted with an enzymecoated microelectrode.

Preparation, calibration, and implantation of choline-selective microelectrodes. Multisite microelectrodes were purchased from the Center for Microelectrode Technology at the University of Kentucky (Quanteon).
Choline oxidase (CO) enzyme immobilization onto two of the four platinum $(\mathrm{Pt})$ recording sites and fabrication of a Nafion barrier were performed as described previously (Parikh et al., 2007; Howe et al., 2010). Before surgery, in vitro calibrations were performed using fixed potential amperometry. The slope (sensitivity), linearity $\left(R^{2}\right)$ for choline, and selectivity ratio for ascorbic acid (AA) and dopamine (DA), were calculated for each individual recording site. The electrodes used in the present experiments were characterized by sensitivity for detecting choline: $7.34 \pm 1.84 \mathrm{pA} / \mu \mathrm{M}$, a background current of $<200 \mathrm{pA}$, selectivity ratio for choline: AA: $275.30 \pm 101.74$, and a highly linear response to increasing choline concentrations $(20-80 \mu \mathrm{M}): R^{2}: 0.997 \pm 0.001$.

Surgeries were performed under aseptic conditions. Animals were placed in vaporization chambers and anesthetized with $5 \%$ isoflurane $\left(1 \mathrm{~L} / \mathrm{min}_{2}\right)$ and maintained on $1-3 \%$ isoflurane $\left(1 \mathrm{~L} / \mathrm{min} \mathrm{O}_{2}\right)$ for the rest of the procedure. The rats' heads were shaved and placed in a stereotaxic frame (David Kopf, Model 962). Their body temperature was maintained at $37^{\circ} \mathrm{C}$ using Deltaphase isothermal pad (Braintree Scientific). Following cessation of the pedal reflex, the scalp was cleansed with Betadine. $\mathrm{A} \sim 10 \mathrm{~mm}$ incision was made along the midline. Three stainless steel screws were threaded in the cranium. An additional hole was drilled above the right prelimbic cortex. The microelectrode assembly was slowly lowered into the prelimbic region of the right PFC (anteroposterior (AP): $+3.0-3.2 \mathrm{~mm}$; mediolateral $(\mathrm{ML}):-0.7 \mathrm{~mm}$, measured from bregma; dorsoventral (DV): $-3.5 \mathrm{~mm}$, measured from dura) and an $\mathrm{Ag} / \mathrm{AgCl}$ reference electrode was implanted in a remote spot in the left hemisphere. The entire assembly was anchored to the skull with dental cement. After a $48 \mathrm{~h}$ recovery period, the water restriction schedule was resumed. Recording sessions typically took place 3-5 d after surgery, allowing time for the animals to acclimate to the headstage and performing while tethered.

Recording of cholinergic transients. Electrochemical recordings were conducted in a wooden operant chamber $(30 \times 25 \times 43 \mathrm{~cm})$ that was completely shielded by copper-wire mesh and equipped with two retractable levers constructed of electrically insulated fiberboard. The water port was constructed from copper. The entire assembly was electrically grounded. The relative location of the central panel light and background illumination provided by the house light was consistent between training and testing environments.

On test day, animals were placed in the recording chamber and connected to the FAST-16 recording system through a shielded cable, a low-impedance commutator, and a miniature headstage (mk-II RAT HAT; Quanteon). Amperometric recordings were collected every $500 \mathrm{~ms}$ $(2 \mathrm{~Hz})$ while a fixed potential of $0.70 \mathrm{~V}$ was applied to the microelectrode using the FAST-16 recording system. Amperometric recordings were time locked by marking task events with TTL pulses. Current recordings from each platinum site were normalized by dividing the raw current value at each time point by the change in current following the addition of DA observed on that site during calibration. The normalized currents recorded from the non-CO-coated sites were then subtracted from the normalized currents recorded at the CO-coated sites ("selfreferencing"). These subtracted values were then converted to concentration of extracellular choline by dividing by the sensitivity of the $\mathrm{CO}$-coated electrode determined in calibration (see further below for trial-by-trial and statistical analyses).

\section{$\mathrm{O}_{2}$ chemistry}

Subjects. Subjects were male Wistar rats (Charles River; $n=9) \sim 60 \mathrm{~d}$ old and 200-300 g at the onset of training. Animals were kept on a $12 \mathrm{~h} \mathrm{light/dark}$ cycle in temperature- and humidity-controlled vivariums. Food was only available as a reward during testing and for $30 \mathrm{~min}$ upon the completion of the training/testing session. Water was available ad libitum. Animals were maintained at no less than $85 \%$ of their free-feeding weight. All training and testing took place during the light cycle between 7:00-19:00 h. All experiments were conducted in accordance with United Kingdom Animals (Scientific Procedures) Act 1986. The training and procedures for the SAT were identical to those described above, except that correct responses were rewarded with food pellets (Noyes $45 \mathrm{mg}$, Formula $\mathrm{P}$ ).

Preparation, calibration, and implantation of microelectrodes. Changes in extracellular tissue oxygen concentration were measured using con- 
stant potential amperometry at carbon paste electrodes (CPEs) as described previously (Lowry et al., 2010; Francois et al., 2012). Briefly, a negative potential $(-650 \mathrm{mV})$ was applied to the CPE to allow the electrochemical reduction of dissolved oxygen to occur at the tip of the electrode. CPEs were constructed from $8 \mathrm{~T}(200 \mu \mathrm{m}$ bare diameter, 270 $\mu \mathrm{m}$ coated diameter) Teflon-coated silver wire (Advent Research Materials). The Teflon insulation was slid along the wire to create an $\sim 2 \mathrm{~mm}$ long cavity that was packed with carbon paste so that carbon was exposed only at the tip of the wire (see Fig. $5 a$ ). Reference and auxiliary electrodes were also prepared from $8 \mathrm{~T}$ Teflon-coated silver wire by removing the Teflon from the tip. All electrodes were soldered to gold connectors, which were cemented into six-pin plastic sockets (both from Plastic One) during surgery. Before implantation, all CPEs underwent a three-point calibration of known concentrations of oxygen $(0,240$, and $1260 \mu \mathrm{M})$. CPEs were chosen for implantation if their calibration curves were linear and the measured oxygen values from the saturated solutions were not greatly different from those expected $\left(R^{2} \geq 0.98\right)$. CPEs were implanted in the medial PFC (mPFC; AP: +3.0-3.2 mm; ML: $-0.7 \mathrm{~mm}$, measured from bregma; DV: $-3.5 \mathrm{~mm}$, measured from dura). The reference electrode was inserted into the posterior cortex. After all electrodes were cemented into place, the gold sockets of the electrodes were inserted into a six-pin plastic socket.

$\mathrm{O}_{2}$ recording and signal processing. On test day, rats were connected to a four-channel potentiostat (Biostat; ACM Instruments) through a sixpin socket (Plastics One) and a flexible screened six-core cable (Plastics One). A PowerLab 8/30 was used for analog/digital conversion and data were collected on a PC running Chart v5 software (AD Instruments). The $\mathrm{O}_{2}$ signal was recorded at a sample rate of $200 \mathrm{~Hz}$. For all test sessions during which oxygen amperometric signal was recorded, animals were tethered and a constant potential $(-650 \mathrm{mV})$ was applied for the duration of the session. Post-acquisition signal analysis was conducted with MATLAB 2009 software. Oxygen signals recorded from each CPE were normalized according to their baseline (i.e., current averaged over a $2 \mathrm{~s}$ period before the beginning of the trial) using the following formula: oxygen level changes $(\mathrm{nA})=($ current $(\mathrm{nA})-$ average baseline $(\mathrm{nA}))^{*}-1$.

Trial-by-trial analysis of cholinergic transients, oxygen responses, and statistical analyses. Data were organized in $0.5 \mathrm{~s}$ time bins. Choline and oxygen-evoked currents for each data point over the $2 \mathrm{~s}$ before the onset of the signal (or the analogous time period on a nonsignal trial) were averaged together and served as the pretrial baseline. The reported absolute changes were calculated as the difference between peak choline concentration value and the presignal baseline period. The peak was based upon the average trace from all trials of a type and defined as the highest point on the average trace relative to baseline. The data from all animals at this time point were used for comparisons. For the choline experiments, hits, misses, and correct rejections recorded from five different sessions in five different animals went into the analysis (animal; \# of trials: Rat 1, 42 hits, 46 correct rejections, 21 misses; Rat 2, 52 hits, 57 correct rejections, 18 misses; Rat 3, 16 hits, 37 correct rejections, 24 misses; Rat 4, 33 hits, 42 correct rejections, 21 misses; Rat 5, 48 hits, 54 correct rejections, 18 misses). For the oxygen experiments, hits and correct rejections were recorded and analyzed from nine different sessions in nine different animals (animal; \# of trials: Rat 1, 47 hits, 35 correct rejections; Rat 2, 52 hits, 31 correct rejections; Rat 3, 53 hits, 50 correct rejections; Rat 4, 62 hits, 48 correct rejections; Rat 5, 34 hits, 52 correct rejections; Rat 6, 59 hits, 42 correct rejections; Rat 7, 56 hits, 38 correct rejections; Rat 8, 37 hits, 49 correct rejections; Rat 9, 60 hits, 44 correct rejections). False alarms occurred relatively rarely ( $\sim 16 \%$ of nonsignal trials). Because of the low number of false alarm trials and the inconclusive electrochemical responses associated with such trials, data from trials and trial sequences involving false alarms were not included in the analyses.

Within-subjects effects were analyzed with repeated-measures ANOVA, and when appropriate, main effects were compared using Fisher's LSD. For analysis of electrochemical data where the number of observations of each within-subject factor was not equivalent, repeated measures were analyzed with linear mixed models. Covariance structures were selected based upon Akaike's Information Criterion, and depending upon the model used, degrees of freedom were not always integers (Verbeke and Molenberghs, 2009). Alpha was set at 0.05. Planned com- parisons were analyzed with paired $t$ tests. Wherever appropriate, exact $p$ values are given (Greenwald et al., 1996).

\section{fMRI}

Participants. Human participants were 15 young adults ( 8 female, mean age $=22.1$ years, range $=18-27$ years) who were right-handed as determined by the Edinburgh Handedness Scale (Oldfield, 1971), had normal or corrected-to-normal vision, and scored at least a 9 on the Extended Range Vocabulary Test (Version 3; mean score $=19.32$, range $=$ 9-32.25; Eckstrom et al., 1976). Participants had not been diagnosed with a psychological or psychiatric disorder, and did not take medications that affect cognition.

Human SAT testing. Participants performed the SAT as previously described (Demeter et al., 2008), implemented using E-Prime (Psychological Software Tools). SAT trials consisted of signal and nonsignal trials (Fig. 1). The signal was a small, dark gray square centrally presented for a variable duration $(60,39$, and $25 \mathrm{~ms})$. Each trial included a monitoring period (1-3 s) consisting of a blank light-gray screen, at the end of which the signal did (signal event) or did not (nonsignal event) appear. The signal occurred for $50 \%$ of the trials, which were pseudorandomly intermixed. A $700 \mathrm{~ms}$, low-frequency auditory response tone was played 500 ms after signal or nonsignal offset, cueing participants to respond with the index finger of one hand to report a signal and the index finger of the other hand to report the absence of such (left/right-hand responsemapping was counterbalanced across subjects). Participants had up to $1.0 \mathrm{~s}$ to respond, with a $700 \mathrm{~ms}$ high-frequency feedback tone sounding after correct responses. No feedback tone was presented for incorrect responses or omissions.

fMRI data acquisition, preprocessing, and data analyses. Three experimental runs consisted of equal numbers of signal, nonsignal, and fixation baseline trials. During fixation periods (duration $2.2 \mathrm{~s}-11.6 \mathrm{~s}$ ), participants were instructed to relax and focus on a centrally presented fixation cross. Each experimental run consisted of 75 trials. Trials were pseudorandomized to ensure that all possible sequences occurred with equal probability. Before scanning began, participants performed in-scanner practice trials to confirm that they remembered task instructions, and that response and feedback tones were audible.

Imaging data were collected using a $3 \mathrm{~T}$ General Electric Signa scanner with a standard quadrature head coil. Only participants with head motion $<3 \mathrm{~mm}$ and $3^{\circ}$ in any direction were included in the analysis. Participants viewed stimuli that were projected on a screen using mirrored glasses. Functional images were acquired using a spiral-in sequence with 35 slices and voxel size $3.44 \times 3.44 \times 3 \mathrm{~mm}(\mathrm{TR}=2 \mathrm{~s}$, TE $=30 \mathrm{~ms}$, flip angle $=90^{\circ}, \mathrm{FOV}=22 \mathrm{~mm}^{2}$ ). A T1-weighted anatomical overlay was acquired in the same functional space $(\mathrm{TR}=225 \mathrm{~ms}, \mathrm{TE}=3.8 \mathrm{~ms}$, flip angle $=90^{\circ}$ ). A 124-slice high-resolution T1-weighted anatomical image was collected using spoiled-gradient-recalled acquisition (SPGR) in steady-state imaging $\left(\mathrm{TR}=9 \mathrm{~ms}, \mathrm{TE}=1.8 \mathrm{~ms}\right.$, flip angle $=15^{\circ}, \mathrm{FOV}=$ $25-26 \mathrm{~mm}^{2}$, slice thickness $=1.2 \mathrm{~mm}$ ).

For preprocessing, structural images were skull-stripped using the Brain Extraction Tool in FSL (FMRIB Software Library; www.fmrib.ox. ac.uk/fsl; Smith et al., 2004) and corrected for signal inhomogeneity. SPGR images were normalized to the Montreal Neurological Institute (MNI) template using SPM5 (Wellcome Department of Cognitive Neurology, London). To spatially normalize functional images to the MNI template, the functional overlay and SPGR were used as intermediates. Functional images were corrected for differences in slice timing (Oppenheim et al., 1989) using SPM8 and head movement using the MCFLIRT algorithm (Jenkinson et al., 2002). Functional images were smoothed with an $8 \mathrm{~mm}$ full-width half-maximum isotropic Gaussian kernel and high-pass filtered (128s).

Onsets of the following were modeled in SPM5 as separate predictors: consecutive hit, incongruent hit, consecutive correct rejection, incongruent correct rejection, fixation, and incorrect responses (Fig. 1, incongruent and consecutive hits and correct rejections). Because fixation periods constituted times in which participants were focused on the display but not processing signal input, hit and correct rejection trials preceded by fixation periods were classified as incongruent hits and consecutive correct rejections, respectively. (Removing these sequences 
a

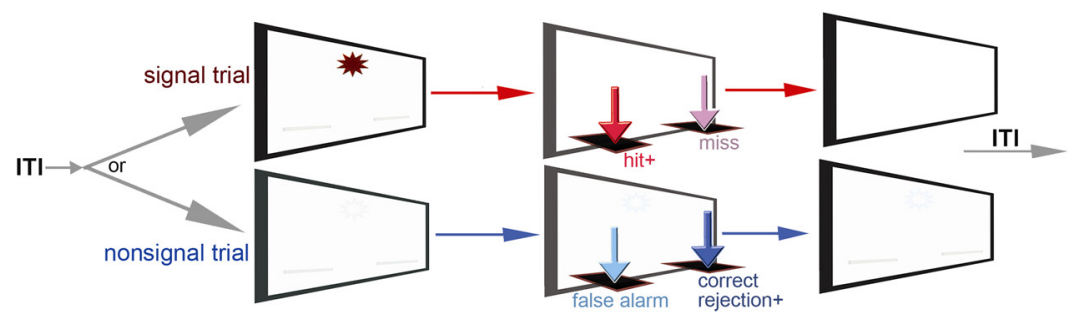

b

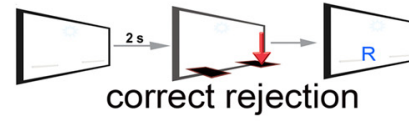

C
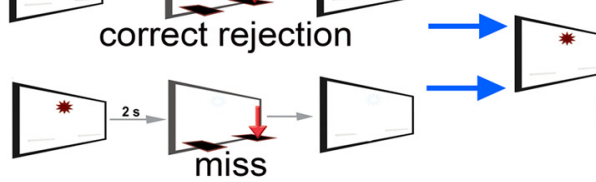

incongruent hit
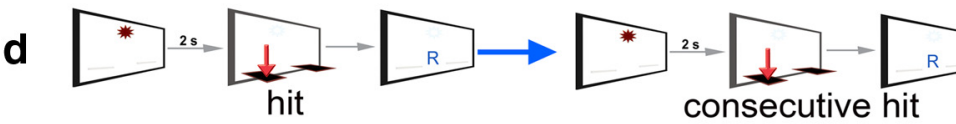

e
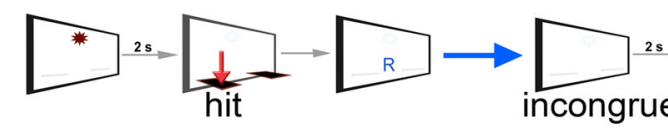

f

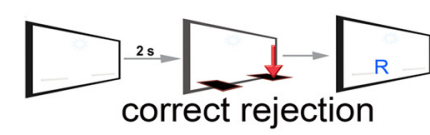

g

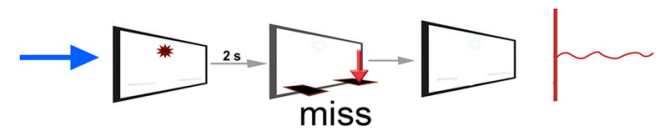

Figure 1. Schematic illustration of the SAT (rat version), main sequences of trials and definition of terms, and schematic overview of the presence or absence of cholinergic, BOLD-fMRI and tissue oxygen responses. The schematic foreshadowing of results assists in maintaining the overview of findings from diverse methods and two species. $\boldsymbol{a}$, The SAT consists of randomized sequences of signal and nonsignal trials (signal durations were 500, 50, and $25 \mathrm{~ms}$ for rats and 60, 39, and 25 ms for humans). Following a signal or nonsignal event, rats were prompted to respond by extending both levers (data shown) while an auditory cue served to open the response window for humans. Correct responses were hits and correct rejections for signal and nonsignal trials, respectively, and in rats were rewarded with water and in humans with a cue indicating monetary reward. Incorrect responses were misses and false alarms, respectively, and triggered the next ITI (see Materials and Methods for more details). $\boldsymbol{b}$ - $\boldsymbol{g}$, Overview over key trial pairs resulting in the presence or absence of neuronal responses during the second trial. All three measures of neuronal activity exhibited increases in signal-hit trials that were preceded by correct rejections or misses (incongruent hits) but not by prior hits (consecutive hits; $\boldsymbol{b}-\boldsymbol{d}$ ). Correct rejections never generated increases in neuronal responses, regardless of whether they were incongruent with the prior trial or part of a chain of consecutive correct rejections $(\boldsymbol{e}, \boldsymbol{f})$. Likewise, misses did not evoke neuronal activity regardless of preceding trial type $(\boldsymbol{g})$. Insufficient data from trial sequences involving false alarms prohibited the analysis of such sequences.

from analysis reduced power but did not qualitatively change results.) False alarms, misses, and omissions were outcomes in $<4 \%$ of trials and were not included in the analyzed trial sequences.

Exploratory whole-brain voxelwise analyses probed significant areas of activation for effects of specific trial sequences (e.g., incongruent hit vs consecutive hit, incongruent correct rejection vs consecutive correct rejection). Significant gray matter clusters were determined for the univariate analyses using a combined height threshold of $p<$ 0.0001 and a cluster volume threshold of 20 voxels; this same threshold was also used for the multivariate connectivity analyses (see following section).

As described (see Results), activation in the basal forebrain met the a priori height threshold but not the extent (cluster size) threshold. Due to theoretical interest in the possible role of the human cholinergic system in incongruent hits, an additional region of interest (ROI) analysis assessed activation in right basal forebrain using an $8 \mathrm{~mm}$ sphere surrounding a basal forebrain peak from a previous, independent paper (MNI coordinates: 18, 6, -10; Teipel et al., 2005). Percentage signal-change values within the basal forebrain ROI were extracted using MarsBar (Brett et al., 2002), and a paired $t$ test probed for enhanced activation for incongruent hits relative to consecutive hits.

To test for neural-behavioral correlations, we created an ROI in right Brodmann area (BA) 10 based on the significant voxelwise univariate analysis. The ROI was defined as the 8 $\mathrm{mm}$ sphere surrounding the peak of the group contrast for incongruent hit $>$ consecutive hit (MNI coordinates: 32, 62, 2). We first used MarsBar (Brett et al., 2002) to extract each participant's percentage signal-change values within the ROI for the incongruent hit $>$ consecutive hit contrast. These differences in percentage signal change for incongruent hit versus consecutive hit trials were then correlated with differences in response time for incongruent hit versus consecutive hit trials. Thus, participants' ROIs were defined independently of the correlation (Vul et al., 2008).

Multivariate functional connectivity analysis. We generated whole-brain maps of functional connectivity through psychophysiological interaction (PPI) analysis (Friston et al., 1997). The BA 10 ROI described above was used as the seed region $(8 \mathrm{~mm}$ sphere drawn around the right BA 10 peak (MNI coordinates: $32,62,2$ ) that was the most strongly activated region from the wholebrain voxelwise univariate analysis for the contrast incongruent hit $>$ consecutive hit). For each participant, we extracted the deconvolved time series for the seed region using a Bayesian estimation algorithm (Gitelman et al., 2003). We multiplied the time series by a block vector representing the contrast incongruent hit $>$ consecutive hit. The model contained separate regressors for the incongruent hit $>$ consecutive hit contrast, seed region time series, interaction, and motion. The incongruent hit $>$ consecutive hit and interaction regressors were convolved with the canonical hemodynamic response function. Paired $t$ tests were used at the group level to identify activity that covaried with the right $\mathrm{BA} 10$ region more during incongruent hits than consecutive hits.

\section{Results}

Survey of main task components, trial sequence terminology, and main results

Figure 1 provides a schematic illustration of the main components of the task depicting the rat version, and the terminology used to define trial sequences. Furthermore, on the right, Figure 1 foreshadows the main results: in all three measures increases in neuronal activity (prefrontal cholinergic activity and tissue oxygen levels in rats, and BOLD-fMRI in humans) were observed solely during incongruent hits. 


\section{Cue-evoked cholinergic transients during incongruent hits} Amperometry and choline-sensitive microelectrodes were used to measure second-based cholinergic release events (transients) in the thalamic input layer of the right prelimbic cortex in SAT performing rats. The focus on this region was based on prior evidence indicating that cholinergic activity in the right, but not left cerebral hemisphere is necessary for scoring hits in the SAT (Martinez and Sarter, 2004), that transients recorded during the performance of a cued appetitive response task were not observed outside the right PFC (Parikh et al., 2007), and that SAT performance increases markers of choline transport capacity solely in right frontal tissue of rats and mice (Apparsundaram et al., 2005; Parikh et al., 2013).

For the analyses that follow, within-subjects effects were analyzed with repeated-measures ANOVA with the factor of time (i.e., baseline vs peak) and, where appropriate, trial type (i.e., incongruent or consecutive) and signal duration (three levels) as factors. As detailed in Materials and Methods, for the analysis of electrochemical data where the number of observations of each within-subject factor was not equivalent, repeated measures were analyzed with linear mixed models (see below for factors and interactions).

Despite being tethered while performing the SAT, rats exhibited typical levels of performance. Accuracy on signal and nonsignal trials was analyzed separately. Hit rates were signal duration-dependent (repeated-measures ANOVA of the effects of signal duration: $F_{(2,8)}=27.32, p<0.001$; percentage hits, $\mathrm{M} \pm$ SEM: 500 ms signals: $85.93 \pm 6.21 \%$; 50 ms: $59.80 \pm 9.04 \% ; 25$ ms: $47.78 \pm 5.88 \%)$. Animals correctly rejected $79.06 \pm 5.09 \%$ of nonsignal events and omitted $4.44 \pm 2.96 \%$ of trials.

Cholinergic transients were observed exclusively in signal trials ending with hits. However, they only occurred on a proportion of hit trials $(60.69 \%)$. Further analyses revealed that the trial type preceding a hit determined whether or not that hit was associated with a cholinergic transient. Transients occurred only on incongruent hits, that is, those preceded by either a factual (correction rejection) or perceived (miss) nonsignal trial (Fig. 2b). In contrast, consecutive hits (hits preceded by another hit) did not elicit cholinergic transients (Fig. 2b). (As noted earlier, false alarms were rare and sequences including them were excluded from analyses.)

Statistical analyses of cholinergic activity patterns were consistent with these impressions. Basal cholinergic activity recorded over the $2 \mathrm{~s}$ before signal presentation (see Materials and Methods) did not differ for incongruent versus consecutive hits (linear mixed model comparing averaged concentration level over the $2 \mathrm{~s}$ before the signal; effect of hit type: $\left.F_{(1,186.49)}=0.05, p=0.83\right)$. Peak cholinergic signal amplitudes (peak defined as greatest difference from baseline concentration level) were significantly higher for incongruent hits than consecutive hits (main effect of hit type: $\left.F_{(1,187.19)}=8.95, p=0.003\right)$. However, peak amplitude of incongruent hits did not vary depending on whether the prior trial was a miss or correct rejection (linear mixed model comparing peak increases, main effect of preceding trial type; $F_{(1,116.79)}=$ $0.62, p=0.43$ ).

Time course analyses indicated that for incongruent hits, cholinergic activity was significantly elevated relative to baseline levels by the time the levers were extended (repeated-measures ANOVA over levels measured $0-4 \mathrm{~s}$ post cue, main effect of time: $F_{(9,1089)}=9.09, p<0.001$; post hoc at $2 \mathrm{~s}$ postsignal; $\left.p<0.001\right)$ and thereafter (all post hoc comparisons, Fisher's LSD: $p<0.05$ ). Cholinergic transients peaked at $253.17 \pm 40.25 \mathrm{~nm}$ above baseline (choline concentrations inferred based on the results of the in vitro calibration) and $6.5 \mathrm{~s}$ following the presentation of the signal. Response latencies, defined as the time between lever extension and lever press, did not differ between consecutive and incongruent hits and occurred $640.51 \pm 34.57 \mathrm{~ms}$ after the extension of the levers (main effect of trial type: $F_{(1,212.99)}=$ $3.35, p=0.07)$.

To test the possibility that cholinergic transients reflect the salience or detectability of the signal, we examined whether the peak amplitude of the cholinergic response varied as a function of signal duration. Because hits are signal duration dependent, there were fewer hits at the $25 \mathrm{~ms}$ duration than at the other signal durations. Therefore, transients to hits at the $25 \mathrm{~ms}$ signal duration were compared with randomly selected numerically matched subsets of hits at the 50 and $500 \mathrm{~ms}$ durations. These analyses showed that transient amplitudes did not vary as a function of signal duration (repeated-measures ANOVA with signal duration as a factor; main effect of signal duration: $F_{(2,86)}=0.44$, $p=0.64)$. The relative number of hits did not differ significantly between hit types (repeated-measures ANOVA with hit type [incongruent vs consecutive] and signal duration as factors, main effect of hit type: $F_{(1,4)}=0.23, p=0.66$; hit type $\mathrm{X}$ signal duration: $\left.F_{(2,8)}=0.06, p=0.93\right)$, rejecting the possibility that incongruent hits were more salient or otherwise easier to detect.

During "miss" trials, cholinergic activity did not significantly depart from baseline (repeated-measures ANOVA $0-4 \mathrm{~s}$ post cue, main effect of time: $\left.F_{(9,909)}=1.70 ; p=0.14\right)$. Likewise, there was no elevation of cholinergic activity during correct rejection trials; in fact, correct rejections were associated with a transient decrease in cholinergic activity (repeated-measures ANOVA over levels measured $0-4 \mathrm{~s}$ post cue, main effect of time: $F_{(9,2124)}=$ $2.45 ; p=0.03)$. Importantly, reverse trial type switches, that is, incongruent correct rejections (Fig. 1e), did not evoke increases in cholinergic activity. Rather, choline-evoked currents on correct rejections preceded by hits tended to show a reverse effect, declining throughout a period during and after lever extension (repeated-measures ANOVA, peak decline vs baseline: $F_{(1,89)}=$ $3.83, p=0.053$; Fig. $2 c$ ).

\section{Right rostral prefrontal activation during incongruent hits in humans}

The second experiment used event-related BOLD fMRI to examine the neural correlates of incongruent hits in healthy adult humans performing the SAT. Our previous cross-species validation studies found qualitatively similar performance between humans and rats, including sensitivity to manipulations of stimulus parameters and distraction (Demeter et al., 2008), although there are important quantitative differences (humans have much higher accuracy) presumably related to humans' greater capacity for top-down control. A block-design arterial spin labeling fMRI study found that SAT performance activates right frontoparietal regions corresponding to those seen in other studies of sustained attention, with select regions further increasing activation in the presence of distraction (Demeter et al., 2011). Here we used event-related BOLD fMRI to examine activity associated with incongruent hits versus consecutive hits in the standard (nodistraction) SAT comparable to the rodent experiment described above.

Correct signal detection by humans was very high, and likely due to ceiling effects, did not significantly differ by signal duration (repeated-measures ANOVA with signal duration as the factor; $F_{(2,28)}=1.13 ; p=0.37 ; 60 \mathrm{~ms}: 96.60 \pm 1.29 \% ; 39 \mathrm{~ms}: 96.27 \pm$ 0.91\%; 25 ms: $95.13 \pm 1.47 \%)$. Humans correctly rejected 

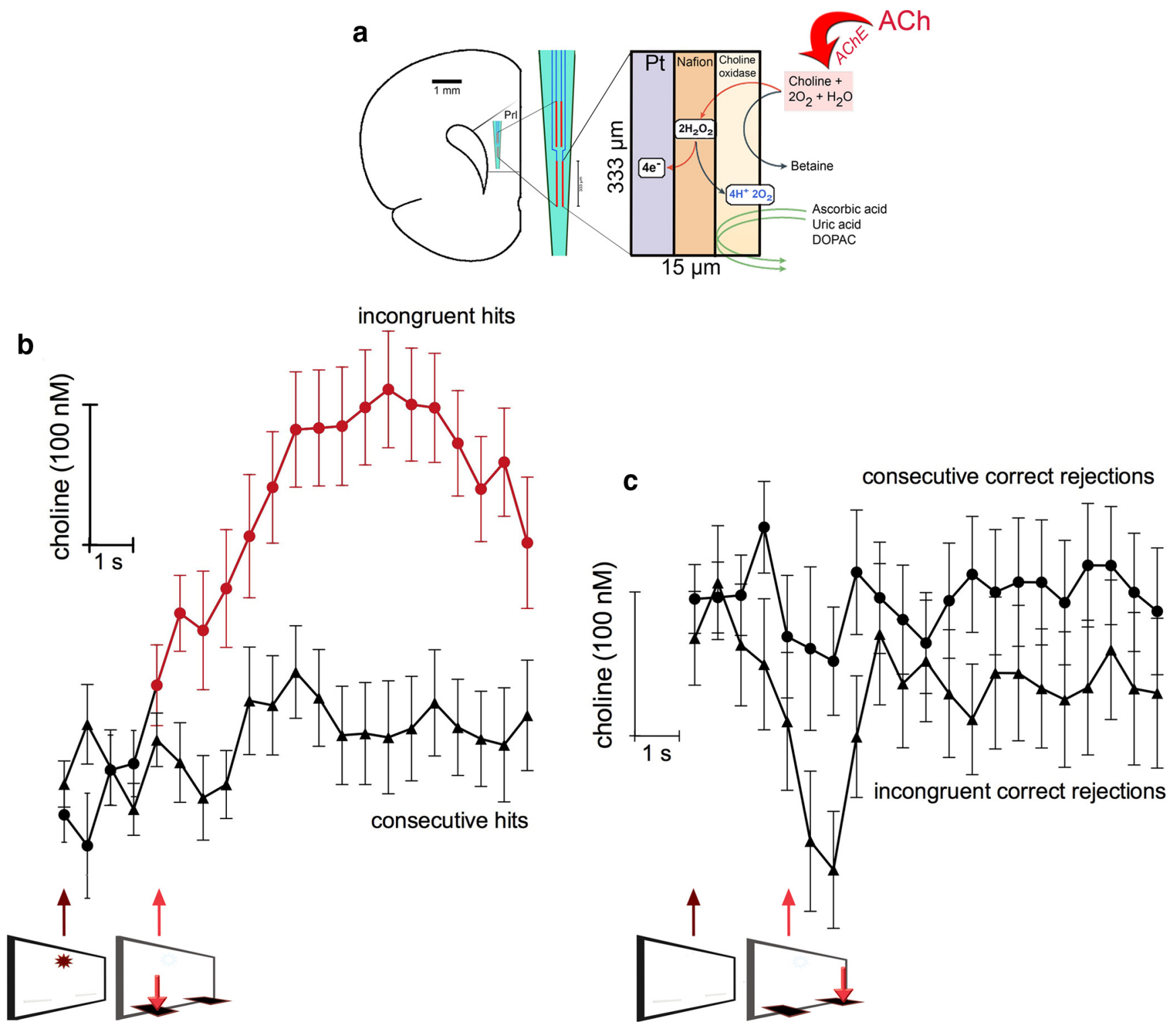

Figure 2. Illustration of electrodes, measurement scheme, and cholinergic transients during incongruent hits. $\boldsymbol{a}$, Illustration of the four Pt recording sites fabricated onto ceramic bases and the approximate placement of the recording sites in the prelimbic (Prl) cortex. CO was immobilized onto 2/4 Pt sites and all sites were equipped with a Nafion layer to repel electro-active interferents ascorbic acid, uric acid, and dihydroxyphenylacetic acid (DOPAC). ACh is hydrolyzed by endogenous acetylcholinesterase (AChE) and the resulting choline is oxidized by immobilized CO on the electrode (Giuliano et al., 2008). The resulting hydrogen peroxide is then detected amperometrically. Current from sites not equipped with C0 was used for self-referencing (see Materials and Methods for details and in vitro calibration). $\boldsymbol{b}$, Choline concentrations (M; SEM) recorded during signal-hit trials as a function of prior trial type (Fig. 1b- $d$ for illustration of consecutive and incongruent hits). The time of signal presentation ( $t=0 \mathrm{~s}$ ) and lever extension $(2 \mathrm{~s})$ are indicated on the bottom. ANOVA (see Results) indicated that only incongruent hits were associated with increases in cholinergic activity ( $n=5$, based on 122 incongruent and 69 consecutive hit trials). Furthermore, compared with baseline cholinergic activity ( 2 s before the signal), cholinergic activity was significantly increased by the time the levers were extended and thereafter, peaking $6.5 \mathrm{~s}$ after the signal (red data points). $c$, Choline concentrations during consecutive and incongruent correct rejections $(n=5$, based on 90 incongruent and 146 consecutive correct rejections; Fig. 1e,f). Response latencies did not differ between consecutive and incongruent correct rejections and were $640.51 \pm 34.57 \mathrm{~ms}$ after the extension of the levers $\left(F_{(1,212.99)}=3.35, p=0.07\right)$. Recordings did not differ between the two conditions. Comparisons against baseline choline concentrations indicated that there was an insignificant trend for a decline in current during incongruent correct rejections, peaking $1 \mathrm{~s}$ following lever extension (see Results).

$98.58 \pm 0.54 \%$ of nonsignal events and omitted very few trials $(0.80 \pm 0.19 \%$ of trials/session) .

The overall hit $>$ correction rejection contrast is not of central theoretical interest here; however, we note that the activation patterns for that contrast generally follow those associated with correct signal detection and include superior frontal gyrus, medial frontal gyrus, precuneus, and inferior parietal lobule (data not shown). For the question of interest, a general linear model modeled incongruent hits, consecutive hits, incongruent correct rejections, consecutive correct rejections, and fixations as separate predictors, with a voxelwise analysis contrasting incongruent versus consecutive hits. This contrast revealed a strong activation in the right rostrolateral/orbitofrontal PFC, approximating BA 10 and a smaller activation in right basal forebrain (Fig. 3; see Table 1). For the whole-brain voxelwise contrast, the right basal forebrain met the height but not extent threshold (peak at MNI coordinates $10,6,-8)$; at a slightly more liberal height threshold $(p<0.0003$ rather than $p<0.0001)$ it was also significant at the cluster-size threshold of 20 voxels (Fig. 3 ). In addition, the directed analysis of the basal forebrain ROI indicated significantly greater activation for incongruent versus consecutive hits $\left(t_{(14)}=\right.$ $3.27, p=0.006)$. 


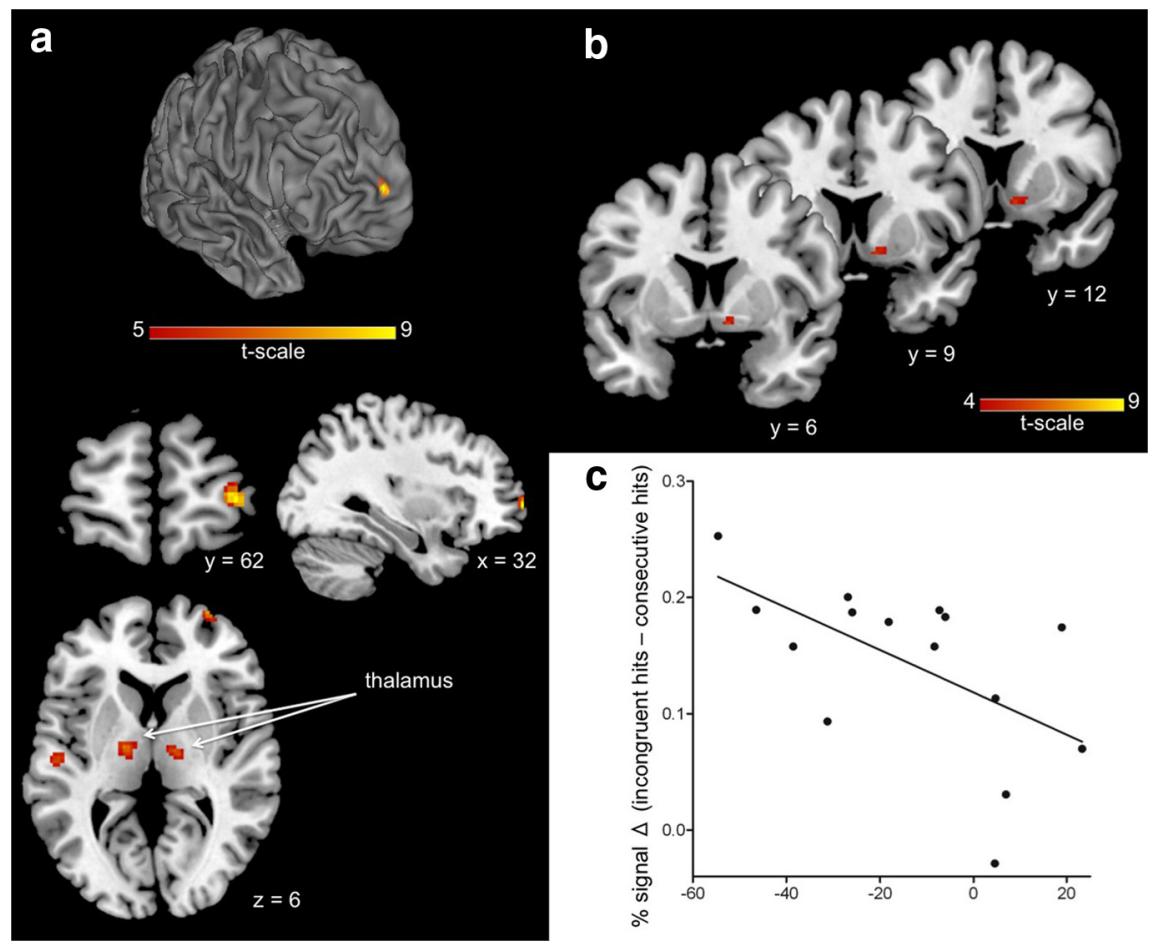

Figure 3. The contrast between incongruent and consecutive hits activated right rostrolateral PFC (BA 10; shown in a on CARET slightly inflated surface representation, and on slices using the MRIcron high-resolution template; $n=15$ ). Thalamic activations are partially displayed (see Table 1 for all activations meeting the combined height threshold of $p<0.0001$ and cluster volume threshold of 20 voxels). $\boldsymbol{b}$, Linking human imaging results to the cholinergic system, at a slightly reduced threshold right basal forebrain also showed significant activation for the contrast between incongruent and consecutive hits. c, Response times were shorter for incongruent hits than consecutive hits, and BA 10 activation differences between incongruent and consecutive hits correlated with reaction time differences $(r=-0.58 ; p<0.05)$. Participants with the greatest increase in prefrontal activation showed the greatest response time benefit for incongruent hits.

PPI analyses were used to reveal the functional attention networks supporting incongruent hits. PPI analyses using the right rostral PFC region as a seed ( $8 \mathrm{~mm}$ sphere with center MNI 32, 62, 2 ) found strong functional connectivity with a region in parietal cortex (BA 7), which is part of the dorsal attention network (Fig. 4; see Table 3). This network is thought to enable the selection of goal-relevant stimuli and their integration with motor responses (Corbetta et al., 2008).

Across subjects, right PFC activation correlated with response-time advantages for incongruent versus consecutive hits (Fig. $3 c$ ), indicating the functional significance of this activation. Participants were faster to respond for incongruent than consecutive hits $\left(t_{(14)}=2.26, p<0.05\right.$; incongruent hits: $457.97 \pm 32.81 \mathrm{~ms}$; consecutive hits: $471.63 \pm 32.99 \mathrm{~ms}$ ). BA 10 activation differences between incongruent and consecutive hits correlated with the difference between the response times for the two types of hits $(r=-0.58 ; p<0.05$; Fig. $3 c)$.

Importantly, none of these patterns were found for other trial sequences, including incongruent correct rejections, which also involve task and response switching (Tables 1-3). Of course, negative findings must always be interpreted with caution. However, to further probe the possibility of a general "switch" explanation, we applied the same BA 10 ROI as for the incongruent versus consecutive hits analysis above to the incongruent versus consecutive correct rejections contrast. The average values across subjects did not differ from zero (one-sample $t$ test, $t_{(14)}=0.58, p=0.57$ ), and there was no correlation with the response-time difference for incongruent versus consecutive correct rejections (slower incongruent than consecutive correct rejections; $r=0.12, p=0.67$ ). Further- more, the right rostral PFC region was not significantly activated for hits in general (all hits $>$ all correct rejections), despite the fact that this analysis had more power (due to more trials) than the hits-only analysis. In summary, the results suggest that like the cholinergic transients measured in the rats in Experiment 1, right rostral PFC activity was selective for incongruent hits. This sequence-specific pattern suggests a specialized role in the reactivation of task rules accompanying shifts from ongoing monitoring to signal-directed performance.

\section{Increased prefrontal tissue $\mathrm{O}_{2}$} concentrations during incongruent hits in rats

Amperometric measures of changes in $\mathrm{T}_{\mathrm{O} 2}$ serve as a proxy for BOLD in rodent studies because (1) tissue oxygenation is closely coupled to neuronal depolarization, field potentials, and regional cerebral blood flow; (2) $\mathrm{T}_{\mathrm{O} 2}$ responses are abolished following neurovascular uncoupling; and ( 3 ) changes in $\mathrm{T}_{\mathrm{O} 2}$ levels are highly correlated with BOLD responses (Masamoto et al., 2008; Lowry et al., 2010; Francois et al., 2012; McHugh et al., 2013).

The performance of animals used for $\mathrm{O}_{2}$ electrochemistry in the SAT mirrored that of animals used for the measurement of cholinergic transients. The percentage of signal trials resulting in hits again depended on signal duration (repeated-measures ANOVA on the effects of signal duration: $F_{(2,21)}=10.79, p<0.001 ; 500 \mathrm{~ms}: 80.05 \pm 4.72 \%$; $50 \mathrm{~ms}: 53.65 \pm$ $5.29 \%$; $25 \mathrm{~ms}: 48.8 \pm 5.3 \%$. Animals correctly rejected $87.20 \pm$ $2.85 \%$ of nonsignal events and omitted very few trials $(2.65 \pm$ $21 \%$ of trials/session).

$\mathrm{T}_{\mathrm{O} 2}$ levels spiked at the onset of the SAT session and then continuously decreased during the entire SAT performance session. When collapsed across trial type, an analysis of $\mathrm{T}_{\mathrm{O} 2}$ levels over five minute blocks indicated a significant effect of block $\left(F_{(8,56)}\right.$ $=12.10, p<0.001$; Fig. $5 b$ ), with a spike at the onset of the SAT session and a continuous decrease over the duration of the session. Analyses of the individual trial types showed that the pattern of decreasing oxygen levels across the performance session was present for all trial types (consecutive hits, consecutive correct rejections, and incongruent correct rejections) except for incongruent hits (Fig. $5 c, d$ ).

Statistical analysis of $\mathrm{T}_{\mathrm{O} 2}$ levels indicated the same pattern as observed for cholinergic transients and BOLD activation: increases specifically for incongruent hits compared with consecutive hits (linear mixed model comparing the effects of trial type on peak amplitudes; $F_{(1,182.31)}=13.92, p<0.001$; Fig. $\left.5 c\right)$. $\mathrm{T}_{\mathrm{O} 2}$ peak levels during incongruent hits were also higher than pre-cue baseline levels (repeated-measures ANOVA, peak increase vs baseline: $F_{(1,330)}=13.47, p=0.03$; see red data points in Fig. $5 c$ ). In contrast, $\mathrm{T}_{\mathrm{O} 2}$ levels during consecutive hits decreased (repeated-measures ANOVA, baseline vs decline: $F_{(1,125)}=3.95$, $p=0.049$ ), beginning at 7 s postsignal (Fisher's LSD; $p<0.05$ for 


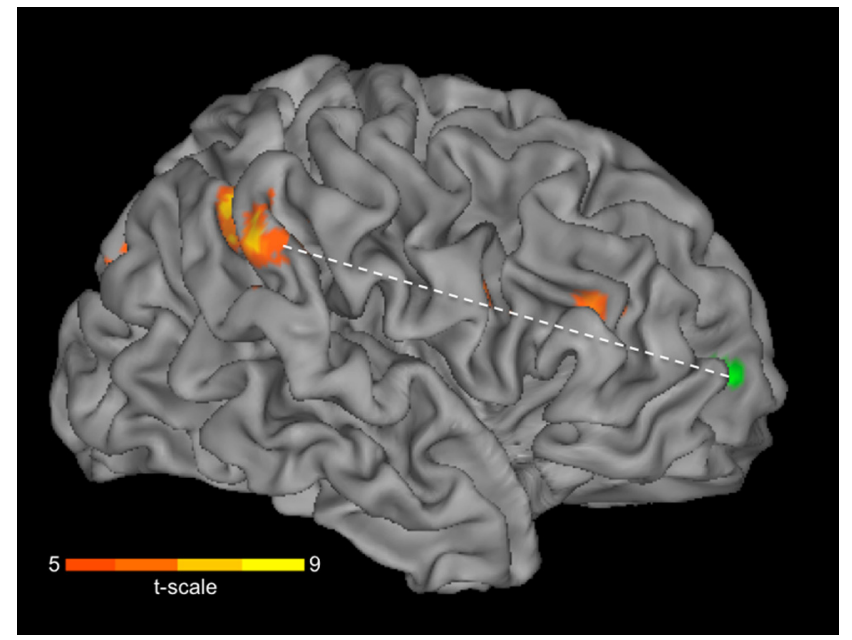

Figure 4. The contrast between incongruent and consecutive hits revealed significant functional connectivity between the right rostrolateral PFC seed region (BA 10; shown in green; $t>5$ ) and parietal cortex regions associated with attention (superior parietal lobule, BA 7; warm colors), as well as middle frontal gyrus (BA 10/46). The functional connectivity $t$ map is displayed at a $p<0.0001$ height, 100 voxel cluster threshold to highlight those regions showing strongest connectivity; see Table 3 for a full list of regions meeting our a priori threshold. Evidence of enhanced functional connectivity with parietal regions associated with controlled attention and the integration of stimuli with responses (Corbetta et al., 1993, 2008; Stephan et al., 1995; Hawkins et al., 2013) strengthens the hypothesis that rostrolateral PFC activity supports shifts from monitoring to cue-directed behavior.

Table 1. Results from BOLD-fMRI analysis of the contrast "incongruent hit > consecutive hit"

\begin{tabular}{|c|c|c|c|c|c|c|c|}
\hline \multirow{2}{*}{$\begin{array}{l}\text { Size } \\
\text { (voxels) }\end{array}$} & \multirow[b]{2}{*}{ Anatomical label } & \multirow[b]{2}{*}{$\mathrm{BA}$} & \multicolumn{3}{|c|}{ MNI coordinates } & \multirow[b]{2}{*}{ T-score } & \multirow[b]{2}{*}{ z-score } \\
\hline & & & $x$ & $y$ & $Z$ & & \\
\hline 38 & Right superior frontal gyrus & 10 & 32 & 62 & 2 & 9.38 & 5.19 \\
\hline 178 & Left thalamus & - & -16 & -10 & 8 & 7.12 & 4.56 \\
\hline 75 & Right thalamus & - & 14 & -14 & 8 & 6.48 & 4.34 \\
\hline 94 & Left superior temporal gyrus & 41 & -52 & -18 & 8 & 6.38 & 4.30 \\
\hline 87 & Left cuneus & 17 & -14 & -98 & -2 & 6.24 & 4.25 \\
\hline 50 & Right posterior cingulate & 29 & 4 & -34 & 20 & 6.09 & 4.19 \\
\hline
\end{tabular}

List of regions activated at a combined height threshold of $p<0.0001$ and a cluster volume threshold of 20 voxels. In addition to the rostrolateral prefrontal (BA 10) and basal forebrain regions emphasized in the main text, this contrast also yielded activation in regions likely associated with increased visual attention (thalamus, cuneus) and processing of the response feedback tones (temporal gyrus). The reverse contrast (consecutive hit $>$ incongruent hit) did not yield any activation at this height and volume threshold. At a more liberal threshold $(p<0.05)$ the consecutive hit $>$ incongruent hit contrast revealed activation in medial frontal gyrus (MNI coordinates: 20,56, 8) and anterior cerebellum (MNI coordinates: $2,-40,-36$ ).

all points after). As noted above, this session-based decline was observed in all trials except incongruent hits.

An additional post hoc analysis addressed the possibility that $\mathrm{T}_{\mathrm{O} 2}$ levels differed before the signal of an incongruent versus consecutive hit. A repeated-measures ANOVA over $\mathrm{T}_{\mathrm{O} 2}$ levels recorded during the $2 \mathrm{~s}$ period before the signals did not indicate a main effect of either hit type (subsequent consecutive or incongruent; $\left.F_{(1,14)}=1.96, p=0.18\right)$ or time $\left(F_{(20,280)}=1.41, p=\right.$ $0.12)$, but there was an interaction between these two factors $\left(F_{(20,280)}=3.22, p<0.001\right)$. Follow-up analyses indicated that time points between 2.0 and $1.6 \mathrm{~s}$ before the signals differed between subsequent consecutive and incongruent hits. This difference may reflect that a proportion of the responses preceding consecutive hits were first (or incongruent) hits and $\mathrm{T}_{\mathrm{O} 2}$ levels associated with those continued to decline. Importantly, for a period of $1.4 \mathrm{~s}$ before the signal, $\mathrm{T}_{\mathrm{O} 2}$ levels did not differ between the subsequent response types.
Again replicating the patterns seen in the analyses of cholinergic activity and BOLD fMRI, there was no difference in $\mathrm{T}_{\mathrm{O} 2}$ peak responses for incongruent versus consecutive correct rejections (linear mixed model ANOVA on the effects of correct rejection trial type; $\left.F_{(1,39.01)}=2.38, p=0.13\right)$. Instead, $\mathrm{T}_{\mathrm{O} 2}$ levels during both correct rejection sequences declined when compared with baseline (repeated-measures ANOVAs; incongruent correct rejections: $F_{(1,246)}=3.89, p=0.05$; consecutive correct rejections: $\left.F_{(1,388)}=14.48, p=0.001\right)$.

\section{Discussion}

The present studies used complementary behavioral and neural measures in rats and humans to provide evidence for a neuronal mechanism supporting shifts from monitoring to cue-directed behavior. Cholinergic transients in rats were observed only during specific trial sequences (incongruent hits) requiring a shift from monitoring to cue-directed behavior. In humans, the same trial sequences elicited activation in right $\mathrm{PFC}$ and basal forebrain (as well as other areas associated with signal and response-cue processing). Additional converging evidence is provided by the $\mathrm{T}_{\mathrm{O} 2}$ responses, which likewise were only elicited by incongruent hits. Together these results suggest that transient right prefrontal activity, related at least in part to cholinergic signaling, contributes to shifts from monitoring to cued response.

Such shifts between monitoring and response in accordance with cued task representations are required by many situations: the drummer waiting for the cue to change the rhythm, or the airport screener who approves hundreds of bags before flagging one that needs inspection. In the human cognitive neuroscience literature, the lateral right rostral prefrontal (BA 10) region activated here has been identified as a "gateway" for shifts between externally directed (perceptual) and internally directed (reflective) attention (Gilbert et al., 2005; Burgess et al., 2007, Burgess, 2011; Chun and Johnson, 2011). In the present experiments, the monitoring period consisted of nonsignal trials and ITIs and required the subject to keep attention directed outward, monitoring the external environment for the possible appearance of a signal. If a signal is detected, monitoring ends, and attention turns inward to retrieve and (re)activate signal-associated response rules and expectations as to which response will lead to reward.

The functional connectivity results further support this interpretation of the right rostrolateral BA 10 activation, linking it to established frontoparietal networks associated with attentional control. PPI analysis revealed significant enhancement of network connectivity during incongruent versus consecutive hits between the right BA 10 seed region and superior parietal lobule, precuneus, inferior frontal gyrus, and middle frontal gyrus. Of particular note, right superior parietal lobule, the region demonstrating strongest functional connectivity, is implicated consistently in shifts of attention and the integration of sensory inputs with associated response rules, perhaps especially in the case of stimuli requiring the nondominant response (Corbetta et al., 1993, 2008; Stephan et al., 1995; Hawkins et al., 2013). The correlation between the right BA 10 activation and behavioral performance in humans further supports its functional relevance.

The right BA 10 and the right basal forebrain were activated during incongruent hits; however, PPI analysis did not indicate functional connectivity between these two regions. The lack of such connectivity may at first seem surprising. However, cholinergic transients are thought to be generated within prefrontal regions, based primarily on interactions between thalamic glutamatergic afferents and heteroreceptor-mediated regulation of cholinergic terminals, 
Table 2. Results from BOLD-fMRI analysis of the contrast "consecutive correct rejection > incongruent correct rejection"

\begin{tabular}{|c|c|c|c|c|c|c|c|}
\hline \multirow[b]{2}{*}{ Size (voxels) } & \multirow[b]{2}{*}{ Anatomical label } & \multirow[b]{2}{*}{ BA } & \multicolumn{3}{|c|}{ MNI coordinates } & \multirow[b]{2}{*}{ T-score } & \multirow[b]{2}{*}{$z$-score } \\
\hline & & & $x$ & $y$ & $z$ & & \\
\hline 38 & Left thalamus & - & -18 & -20 & -4 & 7.33 & 4.63 \\
\hline 150 & Left middle temporal gyrus & - & -40 & -58 & 6 & 7.24 & 4.60 \\
\hline 127 & Left superior temporal gyrus & 22 & -62 & -40 & 20 & 6.57 & 4.37 \\
\hline
\end{tabular}

Although correct rejection contrasts are not of central interest, the lack of PFC activation for sequences involving correct rejections further illustrates the selectivity of the right BA 10 activation during incongruent hits. Activations listed below reach the same threshold as those in Table 1 and the figures ( $p<0.0001$ with a cluster volume threshold of 20 voxels). Temporal gyrus and thalamic activations may reflect enhanced attention to or anticipation of the auditory cue. There were no significant activations for the incongruent correct rejection $>$ consecutive correct rejection contrasts (which would be more conceptually parallel to the critical contrast for hits) at this threshold. At a more liberal threshold ( $p<$ 0.05 ), the incongruent correct rejection > consecutive correct rejection contrast revealed activations in left inferior frontal gyrus (MNI coordinates: $-60,18,6)$ and right superior frontal gyrus (MNI coordinates: $18,56,34)$.

Table 3. Functional connectivity with BA 10

\begin{tabular}{|c|c|c|c|c|c|c|c|}
\hline \multirow[b]{2}{*}{ Size (voxels) } & \multirow[b]{2}{*}{ Anatomical label } & \multirow[b]{2}{*}{ BA } & \multicolumn{3}{|c|}{ MNI coordinates } & \multirow[b]{2}{*}{ T-score } & \multirow[b]{2}{*}{$z$-score } \\
\hline & & & $x$ & $y$ & $z$ & & \\
\hline 1248 & Right superior parietal lobule & 7 & 28 & -58 & 44 & 8.73 & 5.03 \\
\hline 34 & Right superior temporal gyrus & 42 & 68 & -14 & 8 & 7.71 & 4.74 \\
\hline 22 & Right middle temporal gyrus & 21 & 64 & -12 & -4 & 7.46 & 4.67 \\
\hline 79 & Left precuneus & 39 & -32 & -66 & 32 & 7.43 & 4.66 \\
\hline 91 & Right superior temporal gyrus & 22 & 56 & 4 & 6 & 7.07 & 4.54 \\
\hline 34 & Right superior frontal gyrus & 11 & 32 & 58 & -10 & 6.67 & 4.40 \\
\hline 105 & Right middle frontal gyrus & $10 / 46$ & 44 & 34 & 22 & 6.57 & 4.37 \\
\hline 154 & Right inferior frontal gyrus & 9 & 48 & 4 & 32 & 6.56 & 4.36 \\
\hline 54 & Right superior temporal gyrus & 22 & 46 & -42 & 8 & 6.29 & 4.27 \\
\hline 46 & Left inferior parietal lobule & 40 & -32 & -42 & 40 & 6.17 & 4.22 \\
\hline 20 & Right middle frontal gyrus & 9 & 40 & 32 & 42 & 6.07 & 4.18 \\
\hline
\end{tabular}

Regions showing significant functional connectivity with the BA 10 region identified in the univariate contrast. In addition to the lateral parietal region (BA 7) discussed in the main text (see Fig. 4), this analysis also revealed functional connectivity with precuneus, inferior frontal gyrus, middle frontal gyrus, and temporal gyrus. Although we do not interpret these strongly, the precuneus and frontal regions are often associated with shifting attention and rule activation, respectively, and the middle temporal gyrus may reflect increased attention to or anticipation of the auditory cue to respond.

rather than reflecting phasic activity of basal forebrain cholinergic neurons (Couey et al., 2007; Parikh et al., 2008, 2010).

In the rodent studies we focused on the potential role of prefrontal cholinergic transients in shifts, but of course they are part of larger circuitry. Specifically, signal-evoked increases in the activity of thalamic glutamatergic cortical afferents are necessary, but not sufficient, for the generation of cholinergic transients (Parikh et al., 2008; Hasselmo and Sarter, 2011). During consecutive hits, cholinergic activity associated with the first hit may induce persistent spiking (Egorov et al., 2002), maintaining cue-based responding and suppressing, perhaps via stimulation of local GABAergic interneurons, the generation of transients on consecutive hits. The absence of cholinergic activity on consecutive hits favors intracortical (associational) over thalamic input processing (Hasselmo and Bower, 1992), thereby perhaps supporting maintained activation of the internal representation of signal-associated response rules. Our continuing research investigates the prefrontal circuitry supporting incongruent hits and the prefrontal mechanisms generating and terminating cholinergic transients.

Based on our prior studies characterizing the neuronal determinants of cholinergic transients (Parikh et al., 2004, 2007, 2008, 2010; Parikh and Sarter, 2006), this lasting increase in cholinergic activity following an incongruent hit is
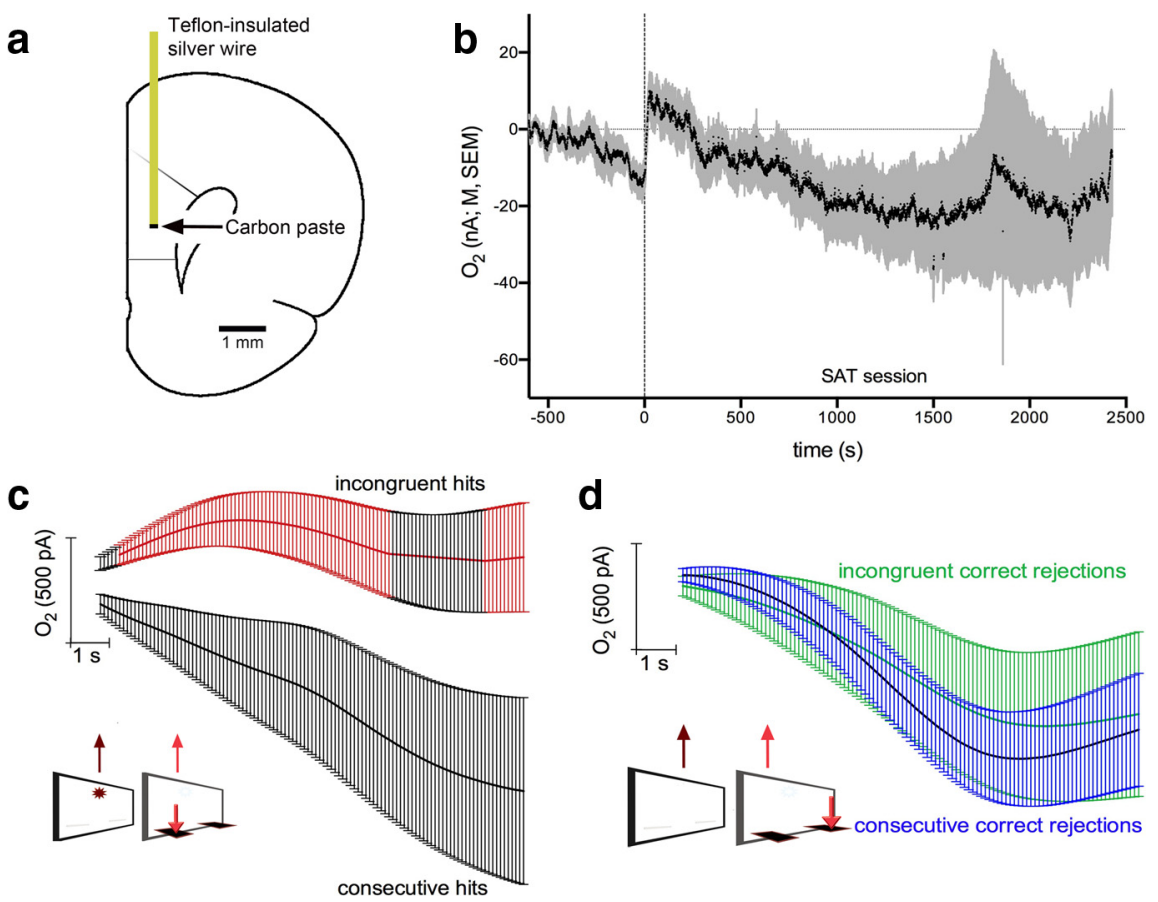

Figure 5. Amperometric measurements of prefrontal oxygen levels during incongruent hits. $\boldsymbol{a}$, illustrates the placement of Tefloninsulated silver electrodes and the carbon tip in the thalamic input layer of the prelimbic cortex. $\boldsymbol{b}$. Currents recorded before the onset of the task and during the entire task session, indicating a continuous decline in current across session (see Results for ANOVA). Note that the ordinate in $\boldsymbol{b}$ is in $\mathrm{nA}$ while those in c and $\boldsymbol{d}$ are in $\mathrm{pA}$. c, During incongruent hits, when compared with consecutive hits, peak oxygen levels were significantly higher ( $n=9$, based on 331 incongruent and 127 consecutive hit trials). Moreover, incongruent hit-associated levels increased significantly from baseline levels, with post hoc comparisons indicating significantly elevated $\mathrm{T}_{02}$ levels present beginning for $0.5 \mathrm{~s}$ following the signal (red data points). $\mathrm{T}_{02}$ levels declined for all other trial types, reflecting the session-based trend for decreasing $\mathrm{T}_{02}$ levels.

interpreted as reflecting continuing release of $\mathrm{ACh}$, rather than electrode properties or delayed choline clearance. Furthermore, as indicated by our prior recordings of cholinergic transients during nonrewarded catch trials and other control conditions, re- 
ward delivery and retrieval do not directly contribute to cholinergic activity (Parikh et al., 2007). The absence of cholinergic transients or $\mathrm{T}_{\mathrm{O} 2}$ responses during consecutive hits and nonsignal trials also rejects the possibility that such activity was activated by reward.

Lasting cholinergic activity after incongruent hits may play a role in integrating information about trial outcome into signalactivated response representations. As this activation decays, the system would return to the dominant monitoring/nonsignal state-in Dayan's terms, the dominant expectation of no signal and expected uncertainty as to when a signal might occur (Yu and Dayan, 2002, 2005; Dayan, 2012). This conceptualization would explain why we did not consistently observe a discrete neuronal signal associated with a return to the monitoring state, but will require further testing with careful parameterization of the timing and relative probability of signal versus nonsignal trials.

The parallels between the rodent and human results assist in interpreting the collective results, but there are important caveats. Most obviously, the PFC is less differentiated in rodents than in primates. The rostral portion of PFC is the largest cytoarchitectonic region of the human brain, having undergone considerable expansion during hominid evolution (Semendeferi et al., 2001). The usefulness of anatomical criteria to define prefrontal regions in rodents and to establish homology with primate prefrontal areas has long been debated (Preuss, 1995). However, the mPFC of rodents supports cognitive operations corresponding to those mediated by more dorsolateral and rostral regions in primates (Brown and Bowman, 2002; Uylings et al., 2003; Kesner and Churchwell, 2011). Similar afferent and efferent organization of dorsolateral and orbitofrontal cortices of primates and mPFC in rodents supports such a functional correspondence (Ongür and Price, 2000). Although human rostral PFC has been linked to many complex processes, some uniquely human (Semendeferi et al., 2001), the collective evidence suggests that we have identified an evolutionarily conserved processing component involved in shifts from monitoring to cue-directed behavior.

Another important limitation is that we cannot directly determine the cholinergic contribution to the fMRI BOLD response. It is currently not possible to use noninvasive methods to visualize subsecond-based cholinergic activity in humans. The parallel $\mathrm{T}_{\mathrm{O} 2}$ responses in the rodent provide at least a partial bridge in this regard. In an additional small experiment ( $n=4$ rats) we found that direct stimulation of prefrontal cholinergic receptors (infusion of oxotremorine and nicotine) elicited a $\mathrm{T}_{\mathrm{O} 2}$ response, providing proof-of-concept support for the hypothesis that cholinergic stimulation contributes to the neuronal responses that underlie oxygen changes and the BOLD response. However, as would be expected from the artificial nature of this stimulation, the shape and time course differ from that produced by cue-evoked stimulation. There are also no current pharmacological manipulations that would selectively influence the amplitude of cholinergic transients in humans (for a discussion of cholinergic drugs for human imaging see Hasselmo and Sarter, 2011). Therefore, although its limitations must be acknowledged, the present approach of similar testing procedures across species and using $\mathrm{T}_{\mathrm{O} 2}$ responses as a proxy for fMRI represents the most informative method available to translate between studies of neurotransmitter studies in rodents and human fMRI.

In summary, converging evidence from three measures of neuronal activity in two species indicates that transient right PFC activity is involved in shifts from monitoring to cue-associated processing. There are important limitations: we cannot directly assess the cholinergic contribution to the BOLD response or its causal role in cue-triggered shifts. However, preliminary data indicate that optogenetic generation of prefrontal transients can enhance hit rates and force false alarms (Gritton et al., 2012). Meanwhile, the present studies represent a critical first step in integrating neuroimaging studies of rostral PFC function with information on the neurochemical mechanisms that may mediate its activity and shifts from monitoring to cue-associated response.

\section{References}

Apparsundaram S, Martinez V, Parikh V, Kozak R, Sarter M (2005) Increased capacity and density of choline transporters situated in synaptic membranes of the right medial prefrontal cortex of attentional taskperforming rats. J Neurosci 25:3851-3856. CrossRef Medline

Brett M, Anton JL, Valabregue R, Poline JB (2002) Region of interest analysis using an SPM toolboxtoolbox [abstract] presented at the 8th International Conference on Functional Mapping of the Human Brain, June 2-6, 2002, Sendai, Japan. Available on CD-ROM in Neuroimage 16(2).

Brown VJ, Bowman EM (2002) Rodent models of prefrontal cortical function. Trends Neurosci 25:340-343. CrossRef Medline

Burgess PW (2011) Frontopolar cortex: constraints for theorizing. Trends Cogn Sci 15:242. CrossRef Medline

Burgess PW, Dumontheil I, Gilbert SJ (2007) The gateway hypothesis of rostral prefrontal cortex (area 10) function. Trends Cogn Sci 11:290-298. CrossRef Medline

Chun MM, Johnson MK (2011) Memory: enduring traces of perceptual and reflective attention. Neuron 72:520-535. CrossRef Medline

Chun MM, Golomb JD, Turk-Browne NB (2011) A taxonomy of external and internal attention. Annu Rev Psychol 62:73-101. CrossRef Medline

Corbetta M, Shulman GL (2002) Control of goal-directed and stimulusdriven attention in the brain. Nat Rev Neurosci 3:201-215. Medline

Corbetta M, Miezin FM, Shulman GL, Petersen SE (1993) A PET study of visuospatial attention. J Neurosci 13:1202-1226. Medline

Corbetta M, Patel G, Shulman GL (2008) The reorienting system of the human brain: from environment to theory of mind. Neuron 58:306-324. CrossRef Medline

Couey JJ, Meredith RM, Spijker S, Poorthuis RB, Smit AB, Brussaard AB, Mansvelder HD (2007) Distributed network actions by nicotine increase the threshold for spike-timing-dependent plasticity in prefrontal cortex. Neuron 54:73-87. CrossRef Medline

Dayan P (2012) Twenty-five lessons from computational neuromodulation. Neuron 76:240-256. CrossRef Medline

Demeter E, Sarter M, Lustig C (2008) Rats and humans paying attention: cross-species task development for translational research. Neuropsychology 22:787-799. CrossRef Medline

Demeter E, Hernandez-Garcia L, Sarter M, Lustig C (2011) Challenges to attention: a continuous arterial spin labeling (ASL) study of the effects of distraction on sustained attention. Neuroimage 54:1518-1529. CrossRef Medline

Disney AA, Aoki C, Hawken MJ (2012) Cholinergic suppression of visual responses in primate $\mathrm{V} 1$ is mediated by GABAergic inhibition. J Neurophysiol 108:1907-1923. CrossRef Medline

Eckstrom RB, French JW, Harman HH, Derman D (1976) Manual for kit of factor-referenced cognitive tests. Princeton, NJ: Educational Testing Service.

Egorov AV, Hamam BN, Fransén E, Hasselmo ME, Alonso AA (2002) Graded persistent activity in entorhinal cortex neurons. Nature 420:173178. CrossRef Medline

Francois J, Conway MW, Lowry JP, Tricklebank MD, Gilmour G (2012) Changes in reward-related signals in the rat nucleus accumbens measured by in vivo oxygen amperometry are consistent with fMRI BOLD responses in man. Neuroimage 60:2169-2181. CrossRef Medline

Friston KJ, Buechel C, Fink GR, Morris J, Rolls E, Dolan RJ (1997) Psychophysiological and modulatory interactions in neuroimaging. Neuroimage 6:218-229. CrossRef Medline

Gilbert SJ, Frith CD, Burgess PW (2005) Involvement of rostral prefrontal cortex in selection between stimulus-oriented and stimulus-independent thought. Eur J Neurosci 21:1423-1431. CrossRef Medline

Gitelman DR, Penny WD, Ashburner J, Friston KJ (2003) Modeling regional and psychophysiologic interactions in fMRI: the importance of 
hemodynamic deconvolution. Neuroimage 19:200-207. CrossRef Medline

Giuliano C, Parikh V, Ward JR, Chiamulera C, Sarter M (2008) Increases in cholinergic neurotransmission measured by using choline-sensitive microelectrodes: enhanced detection by hydrolysis of acetylcholine on recording sites? Neurochem Int 52:1343-1350. CrossRef Medline

Greenwald AG, Gonzalez R, Harris RJ, Guthrie D (1996) Effect sizes and p values: what should be reported and what should be replicated? Psychophysiology 33:175-183. CrossRef Medline

Gritton H, Mallory C, Hetrick, VL, Berke J, Sarter M (2012) Bidirectional optogenetic control of cortical acetylcholine signaling demonstrates vital contributions to attentional performance. Soc Neurosci Abstr. 38.913.16.

Hasselmo ME, Bower JM (1992) Cholinergic suppression specific to intrinsic not afferent fiber synapses in rat piriform (olfactory) cortex. J Neurophysiol 67:1222-1229. Medline

Hasselmo ME, Sarter M (2011) Modes and models of forebrain cholinergic neuromodulation of cognition. Neuropsychopharmacology 36:52-73. CrossRef Medline

Hawkins KM, Sayegh P, Yan X, Crawford JD, Sergio LE (2013) Neural activity in superior parietal cortex during rule-based visual-motor transformations. J Cogn Neurosci 25:436-454. CrossRef Medline

Howe WM, Ji J, Parikh V, Williams S, Mocaër E, Trocmé-Thibierge C, Sarter M (2010) Enhancement of attentional performance by selective stimulation of alpha4beta2 ${ }^{\star}$ nAChRs: underlying cholinergic mechanisms. Neuropsychopharmacology 35:1391-1401. CrossRef Medline

Jenkinson M, Bannister P, Brady M, Smith S (2002) Improved optimization for the robust and accurate linear registration and motion correction of brain images. Neuroimage 17:825-841. CrossRef Medline

Kesner RP, Churchwell JC (2011) An analysis of rat prefrontal cortex in mediating executive function. Neurobiol Learn Mem 96:417-431. CrossRef Medline

Li J, Bravo DS, Upton AL, Gilmour G, Tricklebank MD, Fillenz M, Martin C, Lowry JP, Bannerman DM, McHugh SB (2011) Close temporal coupling of neuronal activity and tissue oxygen responses in rodent whisker barrel cortex. Eur J Neurosci 34:1983-1996. CrossRef Medline

Lowry JP, Griffin K, McHugh SB, Lowe AS, Tricklebank M, Sibson NR (2010) Real-time electrochemical monitoring of brain tissue oxygen: a surrogate for functional magnetic resonance imaging in rodents. Neuroimage 52:549-555. CrossRef Medline

Martinez V, Sarter M (2004) Lateralized attentional functions of cortical cholinergic inputs. Behav Neurosci 118:984-991. CrossRef Medline

Masamoto K, Vazquez A, Wang P, Kim SG (2008) Trial-by-trial relationship between neural activity, oxygen consumption, and blood flow responses. Neuroimage 40:442-450. CrossRef Medline

McGaughy J, Kaiser T, Sarter M (1996) Behavioral vigilance following infusions of 192 IgG-saporin into the basal forebrain: selectivity of the behavioral impairment and relation to cortical AChE-positive fiber density. Behav Neurosci 110:247-265. CrossRef Medline

McHugh SB, Marques-Smith A, Li J, Rawlins JN, Lowry J, Conway M, Gilmour G, Tricklebank M, Bannerman DM (2013) Hemodynamic responses in amygdale and hippocampus distinguish between aversive and neutral cues during Pavlovian fear conditioning in behaving rats. Eur J Neurosci 37:498-507. Medline

Oldfield RC (1971) The assessment and analysis of handedness: the Edinburgh inventory. Neuropsychologia 9:97-113. CrossRef Medline

Ongür D, Price JL (2000) The organization of networks within the orbital and medial prefrontal cortex of rats, monkeys and humans. Cereb Cortex 10:206-219. CrossRef Medline

Oppenheim AV, Schafer RW, Buck JR (1989) Discrete-time signal processing. Englewood Cliffs, NJ: Prentice Hall.

Paolone G, Lee TM, Sarter M (2012) Time to pay attention: attentional performance time-stamped prefrontal cholinergic activation, diurnality, and performance. J Neurosci 32:12115-12128. CrossRef Medline

Parikh V, Sarter M (2006) Cortical choline transporter function measured in vivo using choline-sensitive microelectrodes: clearance of endogenous and exogenous choline and effects of removal of cholinergic terminals. J Neurochem 97:488-503. CrossRef Medline

Parikh V, Pomerleau F, Huettl P, Gerhardt GA, Sarter M, Bruno JP (2004) Rapid assessment of in vivo cholinergic transmission by amperometric detection of changes in extracellular choline levels. Eur J Neurosci 20: 1545-1554. CrossRef Medline

Parikh V, Kozak R, MartinezV, SarterM (2007) Prefrontal acetylcholine release controls cue detection on multiple timescales. Neuron 56:141-154. CrossRef Medline

Parikh V, Man K, Decker MW, Sarter M (2008) Glutamatergic contributions to nicotinic acetylcholine receptor agonist-evoked cholinergic transients in the prefrontal cortex. J Neurosci 28:3769-3780. CrossRef Medline

Parikh V, Ji J, Decker MW, Sarter M (2010) Prefrontal beta2 subunitcontaining and alpha7 nicotinic acetylcholine receptors differentially control glutamatergic and cholinergic signaling. J Neurosci 30:3518-3530. CrossRef Medline

Parikh V, St Peters M, Blakely RD, Sarter M (2013) The presynaptic choline transporter imposes limits on sustained cortical acetylcholine release and attention. J Neurosci 33:2326-2337. CrossRef Medline

Posner MI, Snyder CR, Davidson BJ (1980) Attention and the detection of signals. J Exp Psychol 109:160-174. CrossRef Medline

Preuss TM (1995) Do rats have prefrontal cortex? The Rose-Woolsey-Akert program reconsidered. J Cogn Neurosci 7:1-24. CrossRef

Sarter M, Parikh V, Howe WM (2009) Phasic acetylcholine release and the volume transmission hypothesis: time to move on. Nat Rev Neurosci 10:383-390. CrossRef Medline

Semendeferi K, Armstrong E, Schleicher A, Zilles K, Van Hoesen GW (2001) Prefrontal cortex in humans and apes: a comparative study of area 10 . Am J Phys Anthropol 114:224-241. CrossRef Medline

Smith SM, Jenkinson M, Woolrich MW, Beckmann CF, Behrens TE, Johansen-Berg H, Bannister PR, De Luca M, Drobnjak I, Flitney DE, Niazy RK, Saunders J, Vickers J, Zhang Y, De Stefano N, Brady JM, Matthews PM (2004) Advances in functional and structural MR image analysis and implementation as FSL. Neuroimage 23 [Suppl 1]:S208-S219. Medline

Stephan KM, Fink GR, Passingham RE, Silbersweig D, Ceballos-Baumann AO, Frith CD, Frackowiak RS (1995) Function anatomy of the mental representation of upper extremity movements in healthy subjects. J Neurophysiol 73:373-386. Medline

St Peters M, Demeter E, Lustig C, Bruno JP, Sarter M (2011) Enhanced control of attention by stimulating mesolimbic-corticopetal cholinergic circuitry. J Neurosci 31:9760-9771. CrossRef Medline

Teipel SJ, Flatz WH, Heinsen H, Bokde AL, Schoenberg SO, Stöckel S, Dietrich O, Reiser MF, Möller HJ, Hampel H (2005) Measurement of basal forebrain atrophy in Alzheimer's disease using MRI. Brain 128: 2626-2644. CrossRef Medline

Uylings HB, Groenewegen HJ, Kolb B (2003) Do rats have a prefrontal cortex? Behav Brain Res 146:3-17. CrossRef Medline

Verbeke G, Molenberghs G (2009) Linear mixed models for longitudinal data. New York: Springer.

Vul E, Harris C, Winkielman P, Pashler H (2008) Voodoo correlations in social neuroscience. Perspect Psychol Sci 4:274-290.

Yu AJ, Dayan P (2002) Acetylcholine in cortical inference. Neural Netw 15:719-730. CrossRef Medline

Yu AJ, Dayan P (2005) Uncertainty, neuromodulation, and attention. Neuron 46:681-692. CrossRef Medline

Zaborszky L, Buhl DL, Pobalashingham S, Bjaalie JG, Nadasdy Z (2005) Three-dimensional chemoarchitecture of the basal forebrain: spatially specific association of cholinergic and calcium binding proteincontaining neurons. Neuroscience 136:697-713. CrossRef Medline

Zaborszky L, Hoemke L, Mohlberg H, Schleicher A, Amunts K, Zilles K (2008) Stereotaxic probabilistic maps of the magnocellular cell groups in human basal forebrain. Neuroimage 42:1127-1141. CrossRef Medline 